\section{$\underset{\substack{\text { hommes } \\ \text { \& migrations }}}{ }$}

\section{Hommes \& migrations}

Revue française de référence sur les dynamiques

migratoires

1316 | 2017

L'islam en Europe

\title{
Magyd Cherfi, Ma part de Gaulois
}

Arles, Actes Sud, 2016, 272 p., 19,80€.

\section{Mustapha Harzoune}

\section{Q OpenEdition}

\section{Journals}

\section{Édition électronique}

URL : http://journals.openedition.org/hommesmigrations/3852

DOI : 10.4000/hommesmigrations.3852

ISSN : 2262-3353

\section{Éditeur}

Musée national de l'histoire de l'immigration

\section{Édition imprimée}

Date de publication : 1 mars 2017

Pagination : 204-205

ISBN : 978-2-919040-37-7

ISSN : $1142-852 X$

\section{Référence électronique}

Mustapha Harzoune, " Magyd Cherfi, Ma part de Gaulois », Hommes \& migrations [En ligne], 1316 | 2017, mis en ligne le 01 mars 2017, consulté le 24 septembre 2020. URL : http://journals.openedition.org/ hommesmigrations/3852 ; DOI : https://doi.org/10.4000/hommesmigrations.3852 


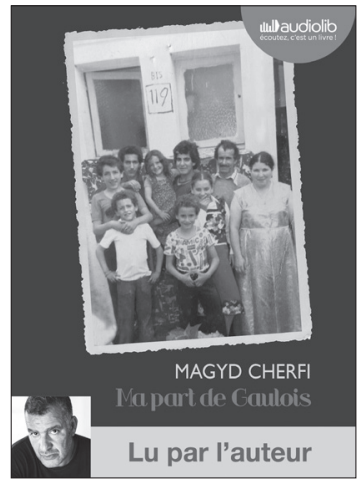

\section{Magyd Cherfi}

Ma part de Gaulois

Arles, Actes Sud, 2016, 272 p., $19,80 €$

Magyd Cherfi ? Bienvenue au club pourrait-on lancer. Le club ?! Celui des auteurs qu'on étrille parce que leur palette, trop riche en couleurs, désarçonne le lecteur un tantinet partisan, incapable de saisir - dans le même mouvement ! - toutes les nuances et la lumineuse alchimie du clair-obscur. En tête de gondole de ce club de romanciers qu'on se dispute, qu'on instrumentalise, au gré de ses pensées riquiquis et de ses petits intérêts idéologiques, figurent un Boualem Sansal ou un Kamel Daoud. Arrive maintenant ce Berbérichon de Toulouse, Occitan poupard à la gueule de Kabytchou qui, avec la malicieuse formule "Ma part de Gaulois ", pratique la prétérition à coups de calembours et de saillies. Les uns se l'arrachent, débrident leur mobylette idéologique en grappillant dans l'œuvre ce qu'ils peuvent vomir sur les banlieues et ces Français par trop «chelous». Pour les autres, ces souvenirs d'un autre temps renforceraient les clichés, les amalgames sur les cités à commencer par la sienne, les Izards au nord de Toulouse. Pire, sur les réseaux, on lit qu'il « cracherait » sur les « siens » et cela, bien sûr, "par intérêt personnel ». Comme disait Rutebeuf: " Avec pauvreté qui m'atterre I Qui de partout me fait la guerre I Au temps d'hiver / Ne convient pas que vous raconte / Comment je me suis mis à honte / En quelle manière ».
C'est une vieille pathologie qui oblige à laver son linge sale en famille. Mais, ce faisant, les plus faibles peuvent continuer à crever à l'ombre des oppressions et des servitudes. Et comme les tensions redoublent, par les temps qui courent, on monte d'un cran, on intente des procès en trahison. C'est un handicap de ne pouvoir embrasser l'arc-en-ciel des possibles, des "ressources » dirait François Jullien, offerts par ces écrivains. Et " c'est une terrible chose que la guerre des couleurs" (Ahmed Azegagh) vers laquelle les uns et les autres mènent.

Que dit Magyd Cherfi ? II raconte sa vie de fils d'immigrés algériens dans une cité toulousaine. Le connu : relégation et discriminations, trafics en tous genres, contrôle communautaire et la "paix " des gros bras et des grandes gueules. II y a ce qui dérange - mais qui n'est pas nouveau (relire Azouz Begag pour le pionnier, Rachid Santaki, Kaoutar Harchi ou Abdelkader Raïliane pour les plus jeunes) -, Magyd Cherfi répète et repère ces lignes de fracture qui séparent ceux qui se battent pour l'éducation et la culture, pour l'égalité entre filles et garçons, et les autres, les imbéciles, lions ou moutons, qui parent leur médiocrité des vertus d'une quincaillerie identitaire clinquante et métallique. À cela, Cherfi ajoute une dimension : sa part de poète. Sa solitude et ses tourments. Sa liberté aussi. « En ces temps de détresse " (Hölderlin), plus que de politiques, de militants, d'imams ou de marchands, c'est bien de poètes dont la société a besoin. Pour danser autrement avec le monde, pour l'embrasser avec plus de tendresse, pour rire des assignations à résidence et apaiser les doigts accusateurs. 
Lire Ma part de Gaulois, c'est retrouver la sensibilité à fleur de peau, la langue imagée, physique, puissante de l'auteur de La Trempe (Actes Sud, 2007). Son amour pour les siens, pour sa mère, femme d'exception et visionnaire. "Arabo-beur, franco-musulman, berbéro-toulousain, gaulois-beur, franco-kabyle, maghréboapostat ", Magyd Cherfi a tort d'évoquer sa "schizophrénie identitaire » là où champignonnent les scories des assignations de fils barbelés. Lui, le poète, a déjà assez à faire avec sa liberté ! Quant à la schizophrénie, c'est aux autres de se faire soigner, de remplumer leur cortex ! Ceux qui restent aveugles au nouveau visage de la France et les autres, quelques gardiens du temple, qui refusent de mettre un peu de vin dans leur eau. M. H.

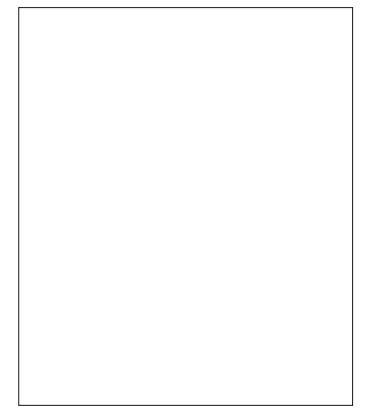

\section{Marie-Christine} Volovitch-Tavares

100 ans d'histoire

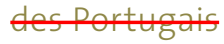
enFrance

Paris, Michel Lafon, 2016, 190p., 29,95.

Ee live embrasse un siècle d'immigration por tugaise en France-depuis un moment clé de la Grande Guerre. l'aceord de main d'euvreétablientrela Franceet le Portu gulen 1916. Pour présenter l'histoire et la mémoirede la plus grande-communauté étrangère nationale en France, souvent qualifiée "d'invisible ", l'historienne Aarie-Christine voloviteh Tavares, spéeialiste de l'histoire de l'immigration Hsitanienne, achoisiun découpage chronologique par dates clefs: 1976 , l'engagement ducorpsexpéditionnaire portugais et l'arrivée des premiers contingents d'ouvriers passant par le dépêt d'Hen daye, 1926, la dictature salazariste-et l'exil politique; 1967 et l'essor d'une-im migration écenomique; 1974, la w révolu tion des fillets "et sonéchoen France;
7986 enfin et l'entrée du Portugaldans la communauté économique européenne qui-offre de nouvelles perspectives poli tiques àl'immigration lusitanienne. tauteure y aborde l'immigration portu gaise sous différents angles : Ie travait en France, lelogement, les luttes sociales et politiques, la vie culturelle, sportive, la religion. En revanche, le contexte socio économique au Portugal motivant le départest moins développé. Siladimen sion fortement prolétarienne de l'immigration lusitanienne est soulignée ainsi que les mouvements de contestation des années 19701980 portés par deu* générations, l'ourage s'écarte d'une vi sion doloriste insistant davantagesur H'inscription nationale et locale de cette histoiremigratoire. Deslieux demémoire sont ainsiévoqués ìl'échellede la France entière, comme le cimetière militaire portugais de Richebourg l'Aveué dans le pas de Calais; la Gare d'Austerlitz i $\mathrm{P}_{2}$ ris; les bidonvilles de Champigny ou des Francs Anoisins ì Saint Denis; le sane tuaire Notre Dame de Mont Roland près de Dôle oì chaque année, depuis 1967, un pèlerinage portugais rend hommage 